\title{
UM OLHAR PARA A HISTÓRIA LOCAL DE RIBEIRÃO CASCALHEIRA - MT: PERSPECTIVAS EDUCATIVAS
}

\section{ARTIGO ORIGINAL}

XAVIER, Emília Damásia de Sousa ${ }^{1}$

SOUZA, Juliana Behrends de ${ }^{2}$

XAVIER, Emília Damásia de Sousa. SOUZA, Juliana Behrends de. Um olhar para a história local de Ribeirão Cascalheira - MT: Perspectivas Educativas. Revista Científica Multidisciplinar Núcleo do Conhecimento. Ano 05, Ed. 01, Vol. 08, pp. 183192. Janeiro de 2020. ISSN: 2448-0959, Link de acesso: https://www.nucleodoconhecimento.com.br/historia/historia-local

\section{RESUMO}

O presente trabalho contou com parceria interinstitucional e teve o objetivo principal resgatar a história local e torná-la em atrativa aos olhos dos alunos da Escola Dona Antonieta Melges de Camargo por meio da interdisciplinaridade. Participaram da presente pesquisa quatro alunos, dois professores, o coordenador e a direção com objetivo de estudar e consequentemente ensinar os demais alunos da escola. A história local está presente na vida de algumas pessoas que há anos habitam esse lugar, mas percebe-se que essa mesma história está ficando esquecida pelos novos moradores. Muitas das vezes, há de se tomar conhecimento dos antepassados para entender o presente. Por esse motivo, através dessa problemática, intentou-se conhecer os arquivos da biblioteca da prelazia na cidade de de São Felix do Araguaia Mato Grosso, em busca de documentos que comprovam a história deste município

1 Mestranda em Ciências da Educação, Professora da Escola Municipal Dona Antonieta Melges Camargo.

2 Doutorado em Ciências da Educação, Professora do Colégio Pedro II (Instituto Federal). 
com a finalidade de mostrar aos alunos da escola meios que fizessem da história local uma ferramenta de facilitação no processo de ensino aprendizagem. Ao final da pesquisa, foi possível revelar talentos artísticos, por sua vez, excitando os alunos a se manifestarem como artista mediante a sua elevação intelectual. No entanto, o projeto fez aproximar a família à escola, como também suscitar parcerias entre as instituições, enfim, elevar-se-á o poderio de compreensão da arte como papel significante e transformador da sociedade.

Palavras-Chave: História local, aprendizagem, aluno.

\section{INTRODUÇÃO}

Este artigo busca apresentar um trabalho realizado pelos órgãos públicos de Ribeirão Cascalheira no ano de 2018, objetivando levar os alunos da Escola Dona Antonieta Melges de Camargo a um conhecimento histórico do local e destacando onde eles nasceram e vivem até hoje, após os estudos bibliográficos, reuniões e viagens. $O$ presente trabalho começa com um breve histórico sobre a migração de Ribeirão Bonito, hoje Ribeirão Cascalheira, a emancipação do local e as causas sobre o mártir Padre João Bosco Penido Bunier. Cita-se, inclusive, a criação da primeira escola do Município criada em 1970. Realizou-se um evento, denominado Noite Cultural, para apresentar aos pais e à comunidade de Ribeirão Cascalheira a história local do município em que eles vivem. $O$ evento foi criado, interpretado e apresentado pelos próprios alunos da escola.

Durante a Noite Cultural, realizada nas dependências da Escola Municipal de Ensino Fundamental de Ribeirão Cascalheira/MT - EMEF Dona Antonieta Melges de Camargo, materializou-se a artes cênicas, artes visuais, artes plásticas de forma interdisciplinar que contou com o apoio do projeto Resgatando a História Local. Em síntese, a Noite Cultural concretizou-se mediante a apresentação artística de cunho e valor educacional, construtiva ao conhecimento dos próprios alunos. 


\section{METODOLOGIA}

O processo metodológico foi realizado através de pesquisas bibliográficas, como, também, outros recursos tecnológicos para contribuir com a execução do projeto. $\mathrm{O}$ estudo de campo foi efetivado por meio de passeios e viagens, visitas em locais estratégicos que subsidiaram os resgates históricos - memórias de personagens, cenários vividos pelos pioneiros do município. Tendo como base a interdisciplinaridade e a Inter institucionalidade, participaram, no primeiro momento da pesquisa, membros da comunidade escolar da Escola Dona Antonieta Melges de Camargo: quatro alunos, dois professores, coordenador e direção, objetivando estudar e, consequentemente, trazer e ensinar os demais alunos da escola.

A presente pesquisa prestou-se a levar os alunos ao reconhecimento da história local e proporcionar a valorização o interesse, legitimando-os como agentes que participam e transformam a história local. Como meta secundária e não menos importante, objetivou-se facilitar a aprendizagem, expondo à comunidade, apresentações em uma Noite Cultural realizada pela própria escola juntamente com a comunidade.

\section{HISTÓRIA DE RIBEIRÃO CASCALHEIRA}

Antes de ser ocupado pelo dito homem civilizado, o território que hoje se constitui o município de Ribeirão Cascalheira estado de Mato Grasso, foi habitado pelos indígenas. Nos dias de hoje, estes povos estão confinados em uma reserva chama de Pimentel Barbosa.

Em 1966, com a abertura da rodovia BR-158, ligando Barra do Garças à São Félix do Araguaia, ela foi aberta para beneficiar as grandes fazendas e inúmeras propriedades de grande porte, que se instalaram às margens da $B R$, motivadas pelo financiamento, oferecidos pelo governo federal, através da SUDAM (Superintendência de Desenvolvimento da Amazônia).

Nesta época, instalaram, nas proximidades do córrego Suiazinho (córrego Ribeirão), os pioneiros Juca e Quintino. Ainda neste ano, embrenharam-se sertão adentro outros 
desbravadores, dentre os quais se registram alguns nomes: Pernambuco, Raimundo Grosso, Abílio, Antonio Cícero, Albertino e outros.

Em 1968, chegou Zacarias Guedes, que abriu uma Pensão para pouso dos que aqui paravam para dormi, foi também o dono do primeiro Comércio em Ribeirão Bonito. Neste mesmo ano, chegaram a comunidade de Ribeirão Bonito Ireno e Benedito, que abriram seu comercio mais distante do córrego, que denominavam de Cascalheira (pela grande quantidade de cascalho presentes nos arredores). Todos vieram com suas famílias: mulheres, filhos e amigos, dando início então, a povoação.

Pela BR-158, passavam famílias de retirantes, caminhões lotados de peões maltratados. Assim, foi chegando e sertão vizinho, gente de muitos lugares. Gente tocada por "tubarões" ou fugindo da seca, povo retirante, buscando terra devoluta para se estabelecer e criar seus filhos. Vieram junto trabalhadores rurais da região do Nordeste e llha do Bananal, que vendiam sua mão de obra por um preço bem inferior. Grande parte deste contingente não recebia pagamento justo e, às vezes, não podia nem mesmo voltar para sua região de origem, já que muitos acabaram ficando e construindo suas casas as margens da rodovia federal, conhecida como BR-158.

Nesta área, abriu-se com a força dos seus braços, as estradas do sertão e, próximo a cada córrego, foram surgindo os núcleos de posseiros, iniciando, assim, a agricultura de subsistência. São os Córregos:

1. Corixão - 1965 - perto dos Xavantes;

2. Água Limpa - 1966;

3. Turvo - 1967;

4. Gengibre - 1968 - gente tocada da Suiá-Missú como os Xavantes;

5. Piabanha - 1969;

6. Mata da Banana e Barreiro - 1970 - gente da llha do Bananal;

7. Matinha que era quase um patrimônio (povoado);

8. Boqueirão - 1971;

9. Barra do Brejo - 1973;

10. Maria Tereza - 1986; 
11. Macífe - 1988.

O local recebeu vários nomes: Ribeirão Bonito, Campo Limpo, Guedolândia, Divinéia e Ribeirão Cascalheira.

No início, todo abastecimento e comércio era recebido de Barra do Garças, apesar da distância de 400 Km. Neste período, o povoado fazia parte do município de Barra do Garças.

Na década de 1970 e meados da década de 1980, o povoado foi palco de vários conflitos agrários entre posseiros e fazendeiros. Alguns flashes da luta pela posse da terra:

O grileiro Guacho partiu com pressão da polícia e pistoleiros para cima dos posseiros. O gerente da fazenda Pinto queimou casa e matou gado dos lavradores e expulsou todo mundo de suas posses. O Zacarias Guedes do Ribeirão Bonito além de expulsar posseiros, tentou matar o Padre Manoel. Na Gleba Piabanha, a Fazenda Amélia Junqueira, em 1971, derrubou ponte, intimou posseiros, queimou casas, e um jagunço baleou o lavrador Cristino. De umas cem famílias, ficaram só umas trinta. Em 1976, a polícia tomou as armas de caça dos posseiros da Gleba Gengibre. No Corixão, teve tanta pressão que um posseiro se suicidou. Muitos peões foram assassinados no córrego do Ribeirão. Uma vez, conforme testemunhas, foram mortos 18 em uma semana". (ALVORADA, A.10.4.13)[3]

O povo juntou-se para se defender e muitos posseiros conseguiram resistir, garantido o direito à terra, e, com eles, o direito à vida. Mas o clima de tensão continuou por muito tempo.

\section{MÁRTIRES DA CAMINHA EM RIBEIRÃO CASCALHEIRA}

Em 11 de outubro de 1976, chegaram o Padre João Bosco e o Bispo Pedro Casaldáliga ao Ribeirão Bonito, que estava em festejos, celebrando a padroeira do 
lugar Nossa Senhora Aparecida. De noite, o Padre foi com o Bispo à delegacia para interceder pelas mulheres que estavam sendo torturadas, Margarida e Santana. Durante a conversa, o soldado Ezy deu uma bofetada, um golpe com o revolver no rosto do Padre seguido de um tiro na cabeça. Fato trágico que abalou toda região do Araguaia e ficou conhecido internacionalmente como o assassinato do Padre João Bosco Penido Burnier.

Considerado um mártir e juntando-se a outros mártires de toda América Latina. O Bispo Pedro Casaldaliga da Prelazia de São Félix do Araguaia, que na época era chamado de Dom Pedro Casaldáliga criou o Santuário hoje conhecida como a igreja dos Mártires da Caminhada. A romaria de seus mártires inicia se na inauguração da igreja e permanecem acontecendo em períodos de cinco em cinco anos. Por esse motivo, a cidade de Ribeirão Cascalheira recebe muitas pessoas vindas de outras cidades, estados e países, surgindo, assim, a caminhada dos mártires.

\section{EMANCIPAÇÃO DE RIBEIRÃO CASCALHEIRA}

Em 1984, através do decreto № 4.774 a situação começa a melhorar, esse decreto cria o Distrito de Ribeirão Bonito, pertencendo ao município de Canarana MT.

Ribeirão Cascalheira recebeu a emancipação político administrativa quatro anos mais tarde, através da Lei Estadual ํㅜ 5.267, de 03 de maio e 1988, de autoria da Bancada Estadual do PDS e do PMDB e sancionada pelo governador Carlos Bezerra, que cria o município com o nome de Ribeirão Cascalheira.

\section{A EDUCAÇÃO EM RIBEIRÃO CASCALHEIRA}

A primeira escola de Ribeirão Bonito hoje Ribeirão Cascalheira foi criada em 1970 pelo morador Zacarias Guedes, as margens da BR 158, próximo ao córrego Ribeirão Bonito. Os primeiros professores foram sua filha Maria das Graças, seu filho Juju, e sua nora Helena. O ensino era baseado em cartilha Caminho Suave, à qual somente o professor tinha acesso. As aulas eram dois períodos, matutino e vespertino. Todo o conteúdo ministrado era exposto no quadro para os alunos copiarem. Neste mesmo 
ano, o Padre Pedro Casaldaliga, que ainda não era bispo, celebrou a primeira missa do lugar, no ranchinho da escola.[4]

Acerca dessas considerações, para D’Ambrósio;

O grande desafio para a educação é pôr em prática hoje o que vai servir para o amanhã. Pôr em prática significa levar pressupostos teóricos, isto é, um saber/fazer acumulado ao longo dos tempos passados, ao presente. Valorizar o local está se tornando uma forma de resgate e sobrevivência da identidade de muitos povos que, para não terem seus costumes e expressões culturais extintas, se valem do entendimento da história local para manter suas tradições. (D’AMBRÓSIO, 2007, p. 80)

Para Freire (2001, p. 87) fala que nosso papel não é falar ao povo sobre a nossa visão do mundo, ou tentar impô-la a ele, mas dialogar com ele sobre a sua e a nossa. Em Ribeirão Cascalheira, percebe-se que a prelazia da Igreja católica, na pessoa do Bispo Pedro Casaldaliga, foi um marco importantíssimo para o desenvolvimento dessa região. Segundo Edevamilton de Lima Oliveira, em sua tese de doutorado, "A invenção da escola no Araguaia-Xingu mato-grossense: memórias, narrativas e lutas pela educação popular e democrática (1960-2018)". Diz;

[...] o lançar luzes à formação das comunidades no Araguaia-Xingu, no terceiro quarto do século $X X$, possibilita-nos entender as razões que moveram a equipe da prelazia, sob a liderança de Pedro Casaldáliga, a envidar esforços para que a população pudesse ter acesso à escola. (OLIVEIRA, 2018, p. 169)

Desde muito cedo, a população e a igreja tiveram que lutar contra a desigualdade nessa região, acreditando que a única forma de transformar a sociedade em geral seria munir- se de uma didática educativa que só a escola poderia oferecer. No que se refere à orientação didática os PCNs diz:

Uma prática educativa que tenha como eixo a formação de um cidadão autônomo e participativo, o ensino deve ser pautado em criar condições 
para que os alunos possam construir significados a partir de múltiplas e complexas interações, pois cada aluno é sujeito de seu processo de aprendizagem, enquanto o professor é o mediador na interação dos alunos com os objetos de conhecimento. (BRASIL, 2000, p. 93)

Portanto, na década dos anos 70, a igreja e a sociedade viram-se preocupada em construir escolas para alfabetizar crianças, jovens e adultos acreditavam que pessoas alfabetizadas, poderiam valorizar o ser humano e, assim, ter menos pessoas passando por necessidade de alimentação e moradia. Provavelmente, se tivessem um espaço para produzir alimentos, sendo este o maior motivo das imigrações de pessoas de outros estados em busca da terra prometida. Assim, não precisariam lutar contra o desemprego em uma sociedade governada por fazendeiros e gestores políticos.

\section{RESGATANDO A HISTÓRIA LOCAL}

Por meio da história, é possível nos situar e entender o que se passava em determinada sociedade e em determinado período. Aqui engajamos os alunos a construir o conhecimento dentro do espaço escolar. Para esse senário, o ensino de História teve que se adaptar às linguagens de ensino e aprendizagem interdisciplinar para a valorização da história local, considerado esse cenário um objeto de estudo e aprendizagem, conhecendo as origens da pulação local, o estudo coloca o povo como agentes ativos e transformador do processo histórico local, dando significado aprendizagem, estimulando, o entendimento e o interesse sobre a contextualização da história local e história nacional.

As aulas de história se tornaram atrativas, uma vez que os indivíduos se inserem nela e, de forma mágica, consegue-se trabalhar a interdisciplinaridade. O que parecia complicado, foi se tornando fácil com as junções das disciplinas de Artes, Português, Matemática, Ciências, História e Geografia. Professores, funcionários, Secretaria Municipal de Educação e Ministério Público do Estado de Mato Grosso contribuíram de forma satisfatória para aproximação da família à escola, como, também, suscitar parcerias entre as instituições. Sobre isso, os PCNs afirmam que: 
A interdisciplinaridade supõe um eixo integrador, que pode ser o objeto de conhecimento, um projeto de investigação, um plano de intervenção. Neste sentido, ela deve partir da necessidade sentida pelas escolas, professores e alunos de explicar, compreender, intervir, mudar, prever, algo que desafia uma disciplina isolada e atrai a atenção de mais de um olhar, talvez vários. (BRASIL, 1999, p. 88-89)

Foi com esse objetivo de atrair olhares para a história local que nos reunirmos de forma interinstitucional para realizar um papel significante e transformador nos alunos e na comunidade escolar. Seguindo esse viés, uma metodologia interdisciplinar pode ser considerada:

Parte de uma liberdade científica, alicerça-se no diálogo e na colaboração, funda-se no desejo de inovar, de criar, de ir além e exercita-se na arte de pesquisar - não objetivando apenas uma valorização técnico-produtiva ou material, mas sobretudo, possibilitando uma ascese humana, na qual se desenvolva a capacidade criativa de transformar a concreta realidade mundana e histórica numa aquisição maior de educação em seu sentido lato, humanizante e libertador do próprio sentido de ser-no-mundo. (FAZENDA, 2002, p. 69-70)

A escola e vários profissionais de diferentes áreas decidiram pela participação, no primeiro momento da pesquisa, de quatro alunos, dois professores, coordenador e direção, objetivando estudar os documentos oferecidos pelo Acervo Cultural, na cidade de São Felix do Araguaia, e, consequentemente, trazer e ensinar os demais alunos da escola.

O sujeito produtor de conhecimento não é um mero receptáculo que absorve e contempla o real nem o portador de verdades oriundas de um plano ideal; pelo contrário, é um sujeito ativo que, em sua relação com o mundo, com seu objeto de estudo, reconstrói (no seu pensamento) este 
mundo. O conhecimento envolve sempre um fazer, um atuar do homem (REGO, 1998, p. 98)

Segundo Rego a aprendizagem dá-se na interação do sujeito com o seu meio, sendo que o conhecimento adquirido tem suas bases nas interações entre sujeito e objeto. Percebe-se, aqui dois pontos fortes dessa relação entre sujeito e o meio. O primeiro ponto forte importante desse trabalho foi proporcionar o conhecimento aos alunos. Após essa interação de conhecer para fazer, os alunos desta instituição de ensino apresentaram uma Noite Cultural na própria Escola Dona Antonieta Melges de Camargo, considerado um momento especial para toda comunidade escolar que foi convidada a integrar conosco um momento único de prazer e expressividade artística construída pelos próprios alunos. Julga-se necessário que as manifestações dos pilares da educação de aprender a aprender e aprender fazendo, tiveram espaços significativos. O segundo foi a possibilidade de revelar talentos artísticos, por sua vez, excitando os alunos a se manifestarem como artista mediante a sua elevação intelectual e interdisciplinar.

\section{CONSIDERAÇÕES FINAIS}

Os alunos ao desenvolver um projeto na escola devem fazer da história local um aprendizado que facilita o processo de ensino-aprendizagem, seja ela local ou nacional, sendo que o entendimento das origens familiares dos alunos, faz com que eles compreendam que são membros de uma comunidade ou um grupo social, isso faz com que eles se interessem mais pelo aprendizado da História e fazendo com que estes se sintam realmente agentes participativos do processo histórico. Ao se relacionar com essa realidade, os alunos descobriram que eles também fazem parte dessa história por serem descendentes dos povos que lutaram por essas terras. (FREIRE, 2006)

Portanto, nota-se que os indivíduos são conhecedores de sua própria história e podem utilizar a história local de forma atrativa para inserir um conhecimento mais geral sobre a história nacional e o que ela contribuiu para a história local. A escola buscou, por meio interdisciplinar, um conhecimento que despertasse no aluno um interesse crítico 
por essa realidade. Nesse sentido, a escola, como portadora de conhecimento, provocou nos alunos a manifestarem opiniões críticas advindas da sua realidade, sobretudo reflexões atuais do meio histórico-social que viveram seus pais.

\section{REFERÊNCIAS}

ALVORADA. 1970, Folha de São Felix do Araguaia. - São Felix - MT : A 16-0-03, 1970. - pp. 2-3.

BARROZO J. C. (org.) Mato Grosso: do sonho à utopia da terra. - Cuiabá- MT: EdUFMT : Carlini\&Caniato, 2008.

BRASIL. Secretaria de Educação Média e tecnologica. Parâmentros Curriculares Nacionais . - Brasília : MEC/SEF, 1999.

CARVALHO, Murilo. Sangue da Terra. A luta armada no campo. São Paulo : Brasil Debates, 1980.

CASALDALIGA, Pedro. Diário 1977-1983, En rebelde fidelidade. Tercer libro deldiario de Pedro Casaldáliga, Desclée, Bilbao. - 1983.

FAZENDA, Ivani C. Arantes. Interdisciplinaridade: História, teoria e Pesquisa [Livro]. - Campinas- SP : Papirus, 2002.

FREIRE, Paulo. Educação e Mudança [Livro]. - Rio de Janeiro : Paz e Terra, 2006.

FREIRE, Paulo. Pedagogia da Autonomia [Livro]. - São Paulo- SP : Paz e Terra, 2007.

FREIRE, Paulo. Pedagogia do Oprimido [Livro]. - Rio de Janeiro- RJ : Paz e Terra, 2001.

LUCK, Heloisa. Pedagogia Interdisciplinar: Fundamnetos Teóricos metodológicos. [Livro]. - Petrópolis- RJ : Editora: Vozes, 1997. 
LUDKE, Menga e Andre Marli E. D. A. Pesquisa em Educação: Abordagens Qualitativa [Livro]. - São Paulo : EPU, 1996.

MOYSÊS, Lucia. Aplicação de Vygostsky a Educação Matemática [Livro]. Campinas - SP : Papirus, 2001.

OLIVEIRA, Edevamilton de Lima. A invenção da escola no Araguaia-Xingu matogrossense: memórias, narrativas e lutas pela educação popular e democrática (1960-2018).. - 2018. - p. 469. - tese de mestrado .

OLIVEIRA, Marta Kohl de. Vygostsky Aprendizado e desenvolvimento: um processo Sócio- histórico [Livro]. - São Paulo : Editora Scipione, 1997.

PINHO, J. B. O PODER DAS MARCAS.- [s.I.] : Summus, $1996 .$.

PRELAZIA, de São Felix do Araguaia. RIBEIRÃO BONITO a caminhada de um povo. - São Felix - MT : [s.n.], Outubro de 1977. - A 10-4-13.

VYGOSTSKY, Levi Semenovich. Psicologia Pedagogica [Livro]. - São Paulo: martins Fontes, 2004.

\section{APÊNDICE - REFERÊNCIAS DE NOTA DE RODAPÉ}

3. Informações obtidas pela apostila feita pela prelazia de São Felix do Araguaia, MT, "RIBEIRÃO CASCALHEIRA, a caminhada de um povo arquivo A-10-4-13", cópia documental na biblioteca da escola Dona Antonieta Melges de Camargo.

4. Estas informações foram fornecidas por Maria Socorro dos Santos bibliotecária da escola Dona Antonieta Melges de Camargo e morada de Ribeirão Cascalheira desde agosto de 1971.

Enviado: Dezembro, 2019.

Aprovado: Janeiro, 2020. 